\title{
Una menorá grabada hallada en Gredos
}

\author{
Javier CASTAÑO* \\ Instituto de Filología - CSIC, Madrid
}

Uno de los objetivos de Las inscripciones hebraicas de España (1956), un clásico para el conocimiento de la cultura material hispano-judía, era ofrecer un completo análisis de las $26(+1)$ inscripciones funerarias judías medievales procedentes de seis localidades de los dilatados territorios de la Corona de Castilla (León, Monzón, Béjar, La Coruña, Sevilla y, por supuesto, Toledo), que se habían conservado. Francisco Cantera expresaba en la introducción su «firme esperanza de que esta publicación será poderoso acicate que estimule [...] el descubrimiento de nuevas lápidas» ${ }^{1}$. Entusiasmo que quedó posteriormente plasmado en un puñado de artículos, suyos y de otros autores, publicados en las páginas de esta misma revista.

Desde entonces, nuestro conocimiento se ha venido incrementando pausadamente como resultado de hallazgos, las más de las veces casuales, ya que sólo en ocasiones excepcionales fue su descubrimiento resultado de una búsqueda premeditada. Descubrimientos producidos tanto en localidades en las cuales ya se conservaban vestigios epigráficos funerarios judíos (Toledo, León), como en otras nuevas (Córdoba, Lucena, Soria y Trujillo), siempre gracias a la colaboración de ciudadanos preocupados por la recuperación para la comunidad del patrimonio material. Pese a todo, medio siglo después de la publicación de aquella obra, el número de piezas conocidas para este territorio no alcanza aún el medio centenar, por lo que cualquier nuevo hallazgo debe ser bienvenido.

La divulgación de la noticia -bulo o realidad- relativa a un hallazgo epigráfico hebraico en la ciudad de Ávila, descubrimiento que aún necesita ser contrastado, ha desviado la atención de otros de indiscutible importancia, relativos al legado material judío preservado en diversas localidades de su pro-

* castano@filol.csic.es

${ }^{1}$ Cantera - J. M. a Millás, Las inscripciones hebraicas de España (Madrid 1956) [= IHE], pág. XIV; y la valoración de J. SchiRmanN, «Thesaurus of Hebrew Inscriptions in Spain» (en hebreo), Tarbiz 27 (1958), 563-569. 
vincia. Del más reciente de ellos fui advertido por unos entusiastas del pasado de Navacepeda que me informaron de la existencia de dos piezas cerámicas fragmentarias que ponen de relieve lo mucho que aún queda por estudiar, pese al olvido al que se ha visto sometido en el pasado el legado material hispano-judío $\mathrm{y}$ de ocasionales quimeras del presente.

Se trata de dos ladrillos fragmentarios que conservan restos de una inscripción hebrea, hallados en Navacepeda de Tormes (Ávila), localidad situada en el valle alto del río Tormes, en la vertiente septentrional de la Sierra de Gredos. Además de los restos que contienen de escritura trazada en elegante letra hebrea cuadrada y de factura parecida, en uno de ellos se conserva el trazo de una menorá (candelabro de siete brazos) decorativa.

Los fragmentos aparecieron al venirse abajo, de manera accidental, parte de la cerca de piedra de un huerto, perteneciente a los restos de una casa, hoy arruinada, y localizada en la zona alta del pueblo. Avanzo a continuación una somera descripción y estudio de las piezas.

El primero de los fragmentos conservados $[A]$ formaba parte de un ladrillo de barro rojizo sin vidriar. Se trata de su parte inferior, rota por ambos lados, con las siguientes dimensiones: altura, $0,112 \mathrm{~m}$.; anchura, 0,131 m.; y grosor, $0,04 \mathrm{~m}$.

La inscripción hebrea habría sido trazada con un estilete cuando la arcilla estaba aún blanda y maleable mediante incisión gruesa y elegante de las letras en la superficie alisada del ladrillo. El texto, que ocupa parte de la cara anterior del ladrillo y aparece roto en el lateral derecho, contiene la fórmula introductoria de un versículo bíblico:

$$
\text { [... S según está es]crito[:] }
$$

fórmula que podemos encontrar, por ejemplo, dentro del texto de la hašcabá (oración a favor del alma del difunto). La regularidad del trazado de las letras, su disposición y tamaño (la base de la bet mide 0, 025 m., y su altura, 0,03 m.), así como la conservación de un único extremo, el inferior, intacto, nos permite pensar en una disposición horizontal del ladrillo original, que estaría colocado junto a, al menos, otra pieza que contenía la continuación del texto, probablemente funerario. La parte posterior del fragmento conserva aún residuos de mortero o argamasa utilizado, quizás, para adherir la pieza sobre una superficie. 
El segundo fragmento $[B]$ es la parte inferior de un ladrillo que conserva intactos sus ángulos laterales y en el que los grabados (escritura y decoración) estarían colocados en disposición vertical. Sus dimensiones son las siguientes: altura, 0,117 m.; anchura, 0,1115 m.; y grosor, 0,0405 m.

En su superficie aparece grabado un nombre femenino:

שרה

Sara

El trazado de la escritura es regular, y las letras hebreas poseen una dimensión similar a las del fragmento $A$, aunque su incisión tiene menor grosor. El palo de la he final del nombre aparece roto por la muesca producida en su hendidura desde el lateral derecho del ladrillo.

A la derecha del nombre se puede identificar la base, tronco y cuatro brazos laterales inferiores de una menorá estilizada en forma de semicircunferencia en $\mathrm{U}$, que aparece rota precisamente por una fractura producida en la hendidura del trazado de los dos brazos superiores. Aparece sustentada sobre una base en la que se observan dos pies. Las dimensiones de la menorá son las siguientes: base, 0,078 m.; altura de la base, 0,02 m.; y tronco (hasta los brazos) 0,05 m. La disposición vertical del ladrillo con el truncamiento de los brazos derechos de la menorá permite suponer la continuación de su trazado en otro ladrillo adherido. Además, se conservan vestigios de mortero en este lateral derecho del ladrillo.

\section{LA INTERPRETACIÓN DE LOS RESTOS ARQUEOLÓGICOS}

Varios indicios apuntan al probable uso funerario de las piezas encontradas en Navacepeda, aunque de momento resulta difícil ser más preciso. El único ejemplar de ladrillo con inscripción hebrea conocido hasta ahora es el hallado en 1916 en las afueras de Toledo que fue estudiado por Abraham S. Yahuda, primero, y más tarde por Francisco Cantera, que le asignó una cronología temprana (siglos XI-XII) ${ }^{2}$. Se trata de un epitafio funerario en buen estado de conservación que contiene el final de la hašcabá y que, originalmente, debía haber formado parte de un grupo de piezas cerámicas que podían contener las primeras líneas del epitafio, incluyendo el nombre de la persona fallecida. A Cantera le llamaron la atención ciertas anomalías observables en el texto fúnebre, y explicaba que éste podía haber sido grabado mediante

${ }^{2}$ A S. YahUdA, «Inscripción sepulcral hebraica en Toledo», BRAH 70 (1917), 323-324, e IHE, págs. 40-44. 
una «audición errada y popular de un texto dictado, o quizás sabido de memoria» ${ }^{3}$. El grabado de la escritura de esta pieza resulta menos elegante y sus trazos alcanzan menor hondura que en los ladrillos $A$ y $B$. La dimensión del, hasta ahora, unicum toledano (altura, 0,2 m.; anchura, 0,28 m.; y grosor, 0,1 m.) supera la de los aquí estudiados. Además, se conocen, al menos, otros dos ladrillos decorados usados en un contexto judío no del todo definido ${ }^{4}$.

Más relevancia para nuestro propósito tiene, sin embargo, el paralelismo que se pueden observar, y también las diferencias, entre los ladrillos judíos y los de barro rojizo que fueron utilizados en enterramientos islámicos de Toledo ${ }^{5}$. Clara Delgado, que había registrado veinticuatro ladrillos islámicos hallados siglos atrás en la Vega toledana, reconocía que ninguno había sido encontrado en su contexto original, añadiendo que debían «hallarse colocados en posición vertical, al nivel de la tumba o sobresaliendo ligeramente del suelo. Se deduce esta disposición del desarrollo horizontal de una banda epigráfica en la parte superior de una de sus caras de cada pieza. Asimismo, es de suponer que esta inscripción fuera colocada hacia la pared exterior de la tumba». Esta misma autora anota las siguientes dimensiones de las piezas islámicas de Toledo: altura, entre 0,20 y $019 \mathrm{~m}$.; anchura, entre 0,28 y $0,15 \mathrm{~m}$. (aunque la mayoría mide $0,27 \mathrm{~m}$.); grosor, fluctuando entre 0,05 y $0,03 \mathrm{~m}$. siendo esta última la medida más regular. Como señala Clara Delgado, los ladrillos árabes conservados eran piezas sueltas de una inscripción o de varias, pero en todo caso no alberga duda alguna acerca de su uso funerario. Problema aparte suscita su datación, aunque la aparición, en dos de ellos, de motivos ornamentales, le inclina a fecharlos a fines del siglo XI ${ }^{6}$. Refiriéndose a Málaga, Guillén Robles señalaba el uso de ladrillos -en este caso, vidriados y adornados con inscripciones y temas geométricos- para recercar tumbas, basándose en testimonios literarios y en la observación directa de cementerios islámicos ${ }^{7}$.

\footnotetext{
${ }^{3}$ IHE, pág. 42

${ }^{4}$ Me refiero al ladrillo de Figueras, estudiado por Millás Vallicrosa (IHE, $\left.\mathrm{n}^{\circ} 245\right)$ y a otro, de discutible interpretación, que contiene una menorá grabada, y del que dio noticia C. GozaLbes Cravioto, «Un ladrillo de época visigoda con simbología judía hallado en Ronda (Málaga)», MEAH. Sección Hebreo 36 (1987), 89-94.

5 C. Delgado Valero, Materiales para el estudio morfológico y ornamental del arte islámico en Toledo (Toledo 1987), págs. 26-28 y 124-131 (nº 97-120). Otros ladrillos funerarios, en este caso vidriados, aparecieron en enterramientos islámicos de otras ciudades andaluzas, según L. Torres Balbás, Ciudades hispano-musulmanas (Madrid 1971), págs. 244-245 y 253 254, y antes, F. Guillén Robles, Málaga musulmana. Sucesos, antigüedades, creencias y letras malagueñas durante la Edad Media (Málaga 1880, reed. 1984), págs. 539-540.

${ }^{6}$ Delgado Valero, Materiales para el estudio morfológico y ornamental, pág. 27.

${ }^{7}$ Guillén Robles, Málaga Musulmana, pág. 540, escribe que los ladrillos «formaban una faja 
Pese al hecho de tener una finalidad, la funeraria, análoga, los ladrillos judíos e islámicos se diferencian por el hecho de que en éstos, la decoración consiste en una estrecha banda epigráfica horizontal que bordea la parte superior de una de las caras, donde se insertan en relieve frases coránicas, mientras que en los judíos, el grabado no queda circunscrito a una banda. Además, a falta de una detallada descripción de las vistas de cementerios hispano-judíos y de indicios más explícitos, no podemos precisar su modo de colocación.

Un importante elemento decorativo que aparece grabado en el fragmento $B$ es una menorá estilizada. De todos los objetos de culto detallados en el texto bíblico, la menorá - cuyo diseño es descrito principalmente en Ex 25:31-39- es el único cuya forma y decoración son fáciles de imaginar, con un bello efecto decorativo, y simboliza el culto interrumpido en el Templo y la esperanza de su restauración ${ }^{8}$. En la antigüedad tardía aparece en contextos funerarios, tanto en la península Ibérica como fuera de ella, aunque Cantera señalaba que su presencia en las inscripciones hispano-judías era excepcional ${ }^{9}$.

Con posterioridad, la menorá vuelve a aparecer representada -junto al resto de objetos de culto del Templo- ilustrando un grupo de manuscritos iluminados peninsulares de la baja Edad Media. La cronología de estas iluminaciones, entre el último tercio del siglo XIII y hasta bien entrado el siglo XV ${ }^{10}$, coincidiría con la de las piezas $A$ y $B$, según se puede deducir del tipo de escritura hebrea utilizada. Un rasgo llama-

a lo largo del sepulcro, bien uniéndose con la piedra que había a sus pies, bien reemplazándola: en este caso, los que debían enlazar con los costados tenían una especie de mortaja, para que encajaran perfectamente unos en otros».

8 J. Gutmann, «A note on the Temple Menorah», Zeitschrift für die Neutestamentliche Wissenschaft 60 (1969), 289-291.

9 Cf. IHE, pág. 352. Las inscripciones judías peninsulares tardoantiguas (no sólo funerarias) que contienen una menorá grabada son las de Tortosa (IHE, n 198, que sólo posee cinco brazos; cf. TB Menaḥot 28a-b); Tarragona (IHE, $\mathrm{n}^{\circ} 243$ y 290); y Mértola (F. Díaz Esteban, «Nuevas inscripciones judías de Portugal y España», en Proceedings of the Tenth World Congress of Jewish Studies. Division B, vol. II. The History of the Jewish People [Jerusalem 1990], 119-126).

${ }^{10}$ Estudiadas en T. Metzger, «Les objects du culte, le sanctuaire du désert et le Temple de Jérusalem, dans les Bibles hébraïques médiévales enluminées, en Orient et en Espagne», Bulletin of the John Rylands Library 52 (Spring 1970), 397-436 y 53 (Autumn 1970), 167-209, págs. 186-187; se completa con EAD., «Les arts du livre (calligraphie, décoration, reliure) chez les juifs d'Espagne, à la veille de l'expulsion», en 1492. L'expulsion des juifs d'Espagne, (dir.) R. Goetchel (Paris 1995), 163-182, pág. 169. Joseph Gutmann analiza también estas Biblias y otras manifestaciones artísticas (así, inscripciones funerarias como $I H E \mathrm{n}^{\circ} 42$ [Toledo]) como «unique expressions of the theology [...] of Spanish Judaism» en su «The Messianic Temple in Spanish Medieval Hebrew Manuscripts», en The Temple of Salomon: Archaeological Fact and Medieval Tradition in Christian, Islamic and Jewish Art, ed. J. Gutmann (Missoula, Mo. 1976), 125-145 y 194-198, págs. 128-129. 
tivo observado en la menorá estilizada de Navacepeda es el hecho de que su pedestal (yarek ) esté aparentemente levantado sobre dos pies, en vez de los tres preceptivos ${ }^{11}$, como suele ocurrir en las menorot representadas de la antiguiedad.

Sería muy importante poder precisar el lugar de origen de las piezas estudiadas, excluida la posibilidad de que hubiera existido cementerio judío en Navacepeda, entre otras razones, por la falta de testimonio documental alguno acerca de poblamiento judío durante la baja Edad Media en la cuenca alta del Tormes (más arriba de El Barco). Navacepeda está situada a 16 kms. de Piedrahita (a través del Puerto de la Peña Negra), ya en Valdecorneja, y a 27 kms. de El Barco. Ambos núcleos contaban con destacadas comunidades judías, también presentes en otras poblaciones del Valle Amblés y del Valle del Tiétar. Durante el siglo XV, el concejo de Navacepeda se integraba dentro del sexmo de La Sierra de la Tierra de Piedrahita, y por lo tanto, estaba sometida al señorío jurisdiccional de los Álvarez de Toledo ${ }^{12}$. La comunidad judía de Piedrahita se documenta al menos desde 1290. En ese año pagaba al rey, junto con los judíos de Bonilla y los de El Barco, una cantidad sólo superada dentro de la diócesis abulense por Ávila, Medina y Olmedo ${ }^{13}$. Aún en la segunda mitad del siglo XV, los judíos de la aljama de Piedrahita siguen pechando al rey tras los de Ávila, Medina, Madrigal y Bonilla, y con la misma cantidad que la aljama de El Barco ${ }^{14}$.

Sería aventurado pretender sin más que los fragmentos provinieran del cementerio judío de alguna de estas localidades, como tampoco sabemos si dichas piezas formaban parte de un mismo conjunto ${ }^{15}$. De la misma manera, ignoramos cómo acabaron siendo depositadas en el lugar en el que fueron halladas. Son éstos alguno de los muchos interrogantes que se mantienen abiertos.

11 Cf. Raší a Ex 25:31.

${ }^{12}$ E. C. Santos Canalejo, «Piedrahita, su Comunidad de Villa y Tierra y los duques de Alba en el siglo XV», EEMed 9 (1986), 1141-1174; y C. de Luss LóPEZ, La Comunidad de Villa y Tierra de Piedrahita en el tránsito de la Edad Media a la Moderna (Salamanca 1987), págs. 112 y 355-357.

13 F. J. HeRnández, Las rentas del rey. Sociedad y fisco en el reino castellano del siglo XIII (Madrid 1993), vol. I, págs. 139 y 167.

${ }^{14}$ M. A. Ladero Quesada, «Las juderías de Castilla según algunos "servicios" fiscales del siglo XV», Sef 31 (1971), 249-264, pág. 259; F. CANTERA Burgos, «Los repartimientos de rabi Jaco aben Nuñes», Sef 31 (1971), 213-247, pág. 230.

15 Únicamente se documenta la existencia del cementerio judío de Piedrahita, la localidad más cercana a Navacepeda y centro de la comarca. El cementerio fue clausurado en 1492 por mandamiento de los doctores Diego Sánchez de Olivares y Carrión, decisión que habría sido apelada por el concejo; Piedrahita, Archivo Municipal, Cuentas de Propios y Rentas del Concejo (1492), cit. LuIs LóPez, La comunidad de Villa y Tierra de Piedrahita, pág. 356. 
UNA MENORÁ GRABADA HALLADA EN GREDOS

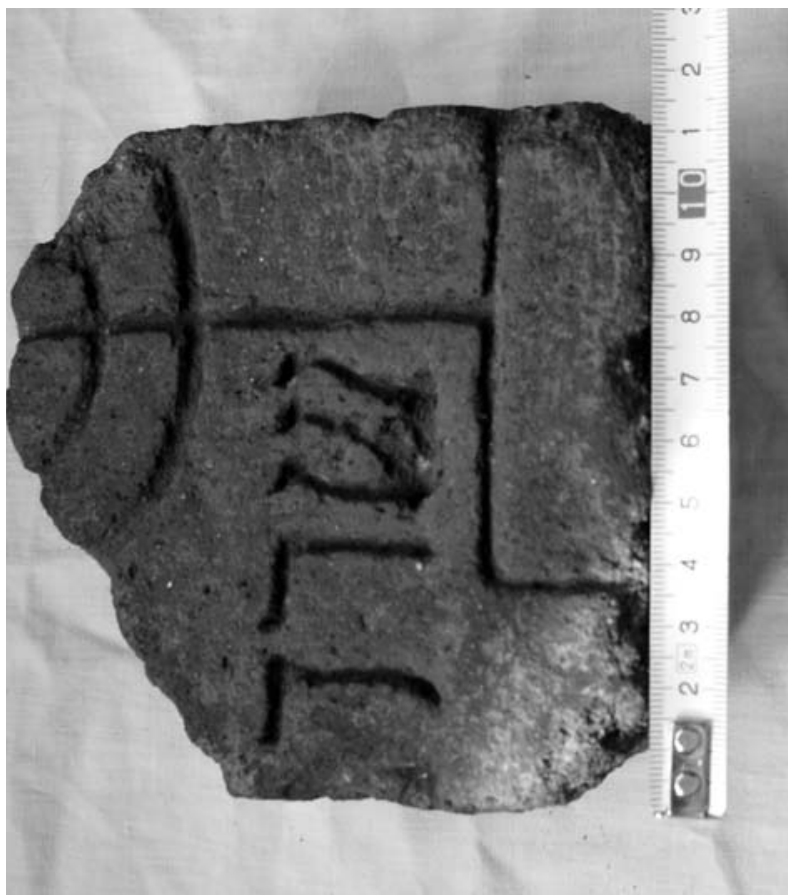

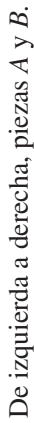

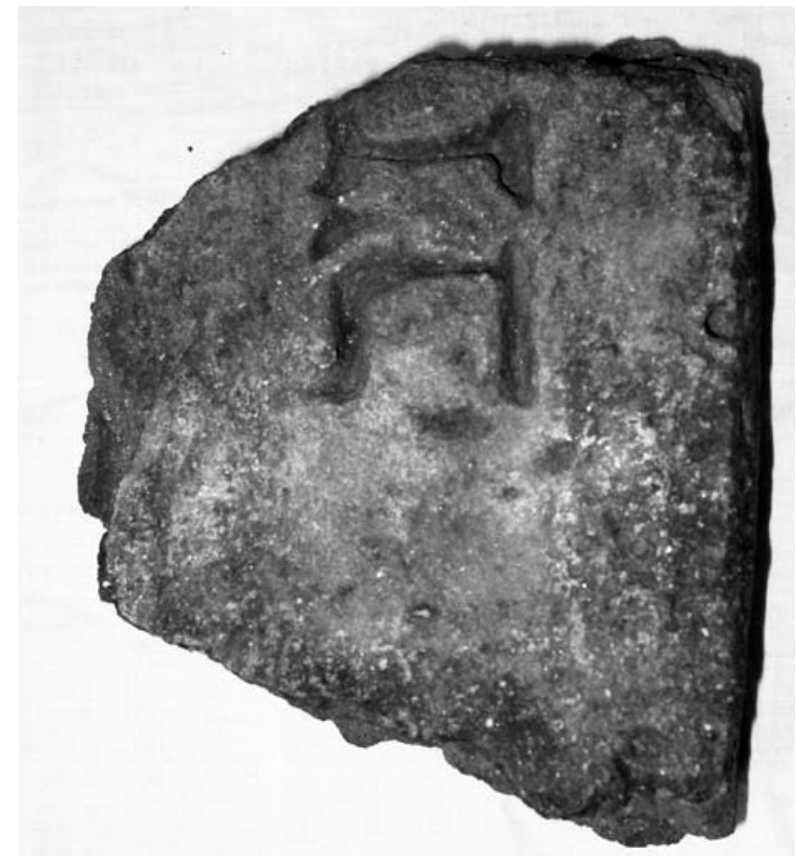

SeFARAD, vol. 67:1, enero-junio 2007, págs. 221-228. ISSN 00037-0894 


\section{RESUMEN}

Noticia del hallazgo de dos fragmentos de ladrillos funerarios judíos bajomedievales con restos de inscripción hebrea en Navacepeda de Tormes, en la vertiente septentrional de la Sierra de Gredos. Una de las piezas aparece decorada con una menorá estilizada. Todos los indicios disponibles apuntan a su hallazgo fuera de su contexto original, que habría sido una sepultura de un cementerio judío de otra localidad.

Palabras Clave: Epigrafía hebrea funeraria, baja Edad Media, Ávila, menorá, cultura material judía.

\section{SUMMARY}

A description and analysis of two late Medieval funerary brick fragments containing Hebrew text and decorated with a stylized Menorah, found in Navacepeda de Tormes (Ávila). According to the available evidence, they were brought from a Jewish cemetery located in another town.

KeYwords: Hebrew Epigraphy, Late Middle Ages, Avila, Menorah, Jewish Archaeological Remnants. 